\title{
Effect of Microstructures and Mechanical Properties of Large Deformation High Entropy Alloy CoCrCuFeNi in Semi-solid Isothermal Heat Treatment
}

\author{
Lajie WANG ${ }^{1}$, Jiao XIONG ${ }^{1}$, Jun LIU $^{2,3}$, X J YANG ${ }^{1,2,3 *}$ \\ 1 Gongqing College, Nanchang University, Nanchang, China \\ 2 School of Mechanical and Electrical Engineering, Nanchang University, Nanchang, China \\ 3 Key Laboratory of Near Net Forming in Jiangxi Province, Nanchang, China
}

*Corresponding Author: XJ YANG, School of Mechanical and Electrical Engineering, Nanchang University, 330031, China

\begin{abstract}
:
The semi-solid slurries of the CoCrCuFeNi high entropy alloy (HEA) were fabricated through the recrystallization and partial melting (RAP) process by cold-rolling and partial remelting. The temperature range of the semi-solid region and the relationship between the liquid fraction and the temperature were determined by the differential scanning calorimetry (DSC) curve. The effect of isothermal temperature and holding time on the evolution of the microstructure and mechanical properties of the rolled samples was analyzed. The results show that the microstructure was significantly deformed, and the tensile strength has been increased by $107 \%$ after $63 \%$ rolling deformation of the $\mathrm{CoCrCuFeNi}$ high entropy alloy (HEA). The high-entropy alloy after cold rolling was maintained at 1150 and $1300{ }^{\circ} \mathrm{C}$ for $20,30,60$, and 120 minutes respectively, the plasticity has been improved compared with the rolled high entropy alloy. The optimal plasticity was reached $13.7 \%$ and $7.9 \%$ at $1150{ }^{\circ} \mathrm{C}$ and $1300{ }^{\circ} \mathrm{C}$ for 30 minutes, respectively. After semi-solid isothermal heat treatment, the grain morphology changed from dendritic of as-cast or rolled to spherulite and the grain size increased significantly with time and the holding temperature increased.

Keywords: high entropy alloy; plastic deformation; semi-solid isothermal treatment; tensile strength; microstructure
\end{abstract}

\section{Introduction}

As a new alloy design concept, high-entropy alloy (HEA) has attracted much attention of many researchers in recent years. Different from the traditional concept of singleelement based alloy, HEAs are the multi-component alloys with equimolar or near-equimolar compositions $[1,2]$. Therefore, high-entropy alloy is also known as multiprincipal component high entropy alloy. Huang et al. ${ }^{[3]}$ have prepared high entropy alloy $\mathrm{AlCoCrCu}_{0.5} \mathrm{NiFe}$ on single crystal silicon and glass by magnetron sputtering, which expanded the application prospect of high entropy alloy in terms of oxide film. Chen et al. ${ }^{[4]}$ manufactured $\mathrm{Al}_{0.25} \mathrm{CoCrFe}_{1.25} \mathrm{Ni}_{1.25}$ HEA coating on 45 steel surface by laser cladding, the results show that the surface hardness of cladding layer can reach 3.2 times of 45 steel due to the mutual solubility of high entropy alloy elements, the solution strengthening effect is produced. Qiu Jingwen, $\mathrm{Fu}$ Zhengfan ${ }^{[5]}$ et al. prepared high entropy alloy reinforced AZ91D composite by laser cladding, which greatly improved the hardness and wear resistance of magnesium alloy, and better applied in aerospace, chemical industry, vehicles and biomedical fields. Therefore, HEA was is regarded as a promising structural material. In order to further improve the mechanical properties of HEA, many researchers used spark plasma sintering ${ }^{[6]}$, high-pressure torsion $^{[7]}$ and equal channel angular extrusion ${ }^{[8]}$ to obtain high-strength HEA.

The semi-solid metal process (SSM), as the most promising material-forming process in the 21 st century, combined with the advantages of solidification and plastic processing, such as the good flowing ability, low resistance to deformation, and easy formation of complex and high precision parts ${ }^{[9,10]}$. The key to the SSM process is to obtain a semisolid slurry with a uniform, small non-dendritic structure. The required spherical microstructure can be generated by either a liquid or a solid route. Solid-state path ways include strain induced melt activation (SIMA) method and recrystallization and partial melting (RAP) 
method ${ }^{[11]}$. Some researchers have studied the effects of plastic deformation, isothermal temperature and holding time in an appropriate semi-solid temperature range on the microstructure evolution and tensile properties of A380 aluminum alloy through SIMA and RAP methods ${ }^{[12]}$. Chen et al. ${ }^{[13]}$ pointed out that the SIMA process can produce ideal, fine semisolid tissues, in which spherical $\alpha-\mathrm{Mg}$ particles have almost no residual liquid. The relationship between the spheroidization degree, holding time and liquid fraction in isothermal treatment is also discussed. However, the research focuses on the low melting point of $\mathrm{Al}$ and $\mathrm{Mg}$ alloys, there are few reports on high melting point alloys, especially for HEA. Rogal ${ }^{[14]}$ obtained the spherical microstructure of $\mathrm{CoCrCuFeNi}$ HEA required for the thixotypic process through RAP method. However, the influence of semisolid conditions (isothermal temperature and time) on microstructure evolution, mechanical properties and coarsening mechanism is not given. These explorations will be interesting and meaningful, which will expand the understanding and application of HEA.

A two-phase FCC CoCrCuFeNi HEA was selected in this paper. Semi-solid slurry is produced by the RAP process through cold rolling and partial remelting. The microstructures and mechanical properties of cast, rolled and semisolid isothermal heat treatment alloys were studied. And the influence of isothermal temperature and holding time on microstructure evolution and tensile properties at room temperature were discussed.

\section{Experimental Procedures}

In this experiment, five high-purity metals (Co, $\mathrm{Cr}, \mathrm{Cu}$, $\mathrm{Fe}$ and $\mathrm{Ni}$ ) with higher than $99.9 \%$ (mass fraction) purity were selected as raw materials. Each element is weighed according to the equal molar ratio, with a total weight of $4 \mathrm{~kg}$. CoCrCuFeNi high entropy alloy was obtained by melting in a vacuum suspension induction melting furnace protected by high purity argon. In the smelting process, the ingot was re-melted 4-5 times to ensure uniform smelting. The cylinder sample with a dimension of $90 \mathrm{~mm}$ in diameter and $70 \mathrm{~mm}$ in height was obtained.

The rectangular sample with a dimension of 70 $\mathrm{mm} \times 15 \mathrm{~mm} \times 6 \mathrm{~mm}$ was cut from the as-cast button. Large deformation rolling high entropy alloy sheet with a thickness of $2.2 \mathrm{~mm}$ was obtained by 8 passes of rolling treatment, in which the first 7 passes rolling reduction are all $0.5 \mathrm{~mm}$, and the last pass rolling reduction is $0.3 \mathrm{~mm}$. The rolled plate is cleaned with anhydrous ethanol and then vacuum sealed with quartz tube. The quartz tube is kept flat and put into YFFG40/13G-YC three-phase resistance furnace for semi-solid isothermal treatment and water quenching after treatment at different temperatures and holding times.

The microstructure was investigated by X-ray diffraction (XRD)with the $\mathrm{CuKa}$ radiation and optical microscope (OM). The compositions of phase were analyzed by energy dispersive spectroscope (EDS). The thermal analysis was performed by the differentialscanning calorimetry (DSC) with a constant heating rate of $20 \mathrm{~K} / \mathrm{min}$. The mechanical properties were characterized by tensile behavior. The tensile samples with a total length of $60 \mathrm{~mm}$, a thickness of $2.2 \mathrm{~mm}$, a clamping end width of $15 \mathrm{~mm}$, a standard tensile distance of $30 \mathrm{~mm}$, a section width of $5 \mathrm{~mm}$ and a radius of $5 \mathrm{~mm}$ arc transition as shown in Figure1.

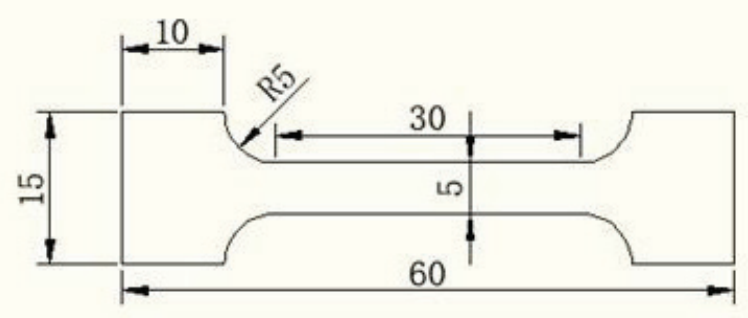

Figure1. Dimensional drawing of tensile samples ( $\mathrm{mm})$.

\section{Results and Discussions}

\subsection{SEM of as-cast materials and thermodynamic results}

The as-cast CoCrCuFeNi HEA has typical dendrite (DR) and interdendrite (ID) structures as shown in Figure 2. The chemical compositions of different phases were determined by SEM energy dispersion spectrometer (EDS) at the points of dendrite (DR) and interdendrite (ID) respectively. The DR structure was FCC2 matrix phase with high volume fraction. In the DR region, the ID phase with a low volume fraction is FCC1 phase. The chemical composition of FCC1 and FCC2 phases indicates that FCC1 phase is $\mathrm{Cu}$ rich phase, However, the concentration of $\mathrm{Co} \mathrm{Cr}$, Fe and $\mathrm{Ni}$ in FCC2 is similar as shown in Table 1. The reason leading to a strongsegregation of $\mathrm{Cu}$ in the FCC1 phase from the EDS results is the positive mixing enthalpy of $\mathrm{Cu}-\mathrm{Cr}, \mathrm{Cu}-$ $\mathrm{Co}, \mathrm{Cu}-\mathrm{Fe}$, and $\mathrm{Cu}-\mathrm{Ni}^{[15]}$. The volume fraction of the FCC2 phase was about $87 \%$.

Figure 3 shows the DSC curves of as-cast and rolled $\mathrm{CoCrCuFeNi} \mathrm{HEA.} \mathrm{There} \mathrm{are} \mathrm{two} \mathrm{exothermic} \mathrm{peaks} \mathrm{in} \mathrm{the}$ as-cast alloy and the rolled alloy, and the positions of the exothermic peaks are basically the same, which indicates that the internal composition of the alloy has not changed after rolling. The first exothermic peak appears at about $1114{ }^{\circ} \mathrm{C}$, the integral area of the peak is small and the temperature point is close to the melting point of copper $\left(1083{ }^{\circ} \mathrm{C}\right)$. Combining DSC curve, EDS test and volume fraction calculation results, it could be judged that this peak represented FCC1 phase, and the second peak represented FCC2 phase. The alloy began to melt partially at about $1114^{\circ} \mathrm{C}$ and the crystal structure changed, the second exothermic peak appeared at about $1343^{\circ} \mathrm{C}$ and ended at about $1388^{\circ} \mathrm{C}$, indicating that the alloy was completely melted at this time. The semi-solid holding temperature of the as cast sample is obtained by integrating the DSC curve in Figure 3. In the liquidus rate curve as shown in Figure 4 , the liquidus rate is about $9.2 \%$ at $1150^{\circ} \mathrm{C}$, which is 
relatively low, and there is a rapid increase of liquid phase ratio before $1150{ }^{\circ} \mathrm{C}$. In combination with DSC curves, the FCC1 phase has been completely melted at $1150{ }^{\circ} \mathrm{C}$, and the liquid phase ratio increases slowly with the increase of temperature. When the temperature reached $1350^{\circ} \mathrm{C}$, the liquid phase ratio curve increased rapidly, indicating that the FCC2 phase began to melt, and the liquid phase ratio approached $60 \%$. It is very difficult to get accurate liquid phase ratio in the two regions where the liquid phase ratio changes rapidly, finally the liquid phase ratio changes rapidly and the solid phase ratio is easy to lose stability. When the temperature is higher than $1350^{\circ} \mathrm{C}$, the melting of FCC2 phase leads to the high liquid ratio of materials, which is easy to cause the deformation and melting and cannot maintain the macroscopic structure of the sheet metal during the semi-solid heat preservation treatment. Therefore, the semi-solid treatment temperature should be between $1133^{\circ} \mathrm{C}$ and $1343^{\circ} \mathrm{C}$. Therefore, in this experiment, $1150^{\circ} \mathrm{C}$ with a liquid phase ratio of $9.2 \%$ and $1300^{\circ} \mathrm{C}$ with a liquid phase ratio of about $41 \%$ were selected as semi-solid insulation temperature.

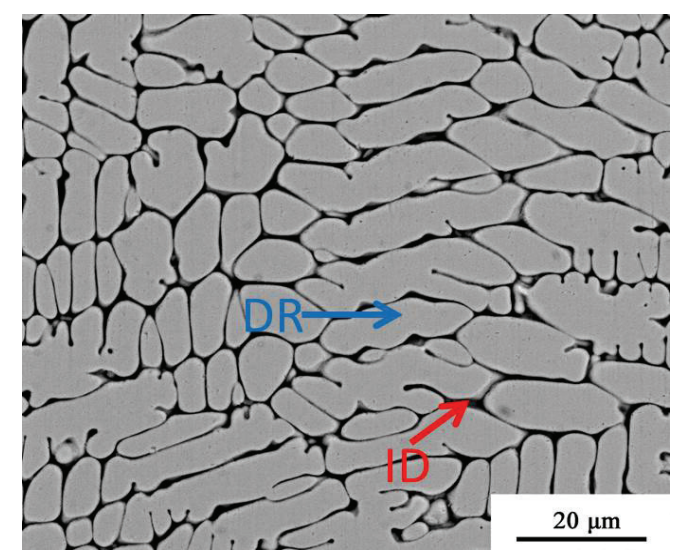

Figure 2: The SEM of as-cast sample.

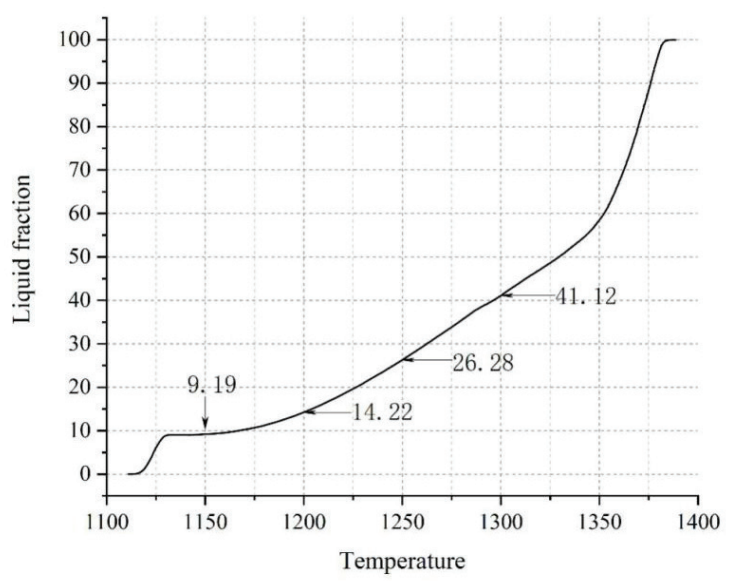

Figure 4: Liquid phase ratio curve of as-cast.
Table 1. Contents of each element at two regional points in the as-cast microstructure of $\mathrm{CoCrCuFeNi}$ high-entropy alloy (wt. \%).

\begin{tabular}{cccccc}
\hline $\begin{array}{c}\text { Sampling } \\
\text { point }\end{array}$ & $\begin{array}{c}\mathrm{Co} \\
(\%)\end{array}$ & $\mathrm{Cr}(\%)$ & $\mathrm{Cu}(\%)$ & $\mathrm{Fe}(\%)$ & $\begin{array}{c}\mathrm{Ni} \\
(\%)\end{array}$ \\
\hline DR region & 23.89 & 21.57 & 11.66 & 21.63 & 21.25 \\
ID region & 9.81 & 10.36 & 56.03 & 10.04 & 13.76 \\
\hline
\end{tabular}

\subsection{XRD diffraction}

Figure 5 shows the X-ray diffraction patterns of samples in different states. Comparison before and after semi-solid isothermal treatment, the positions of each diffraction peak did not shift, and they were all combinations of FCC1 phase and FCC2 phase. The phase composition structure of CoCrCuFeNi high-entropy alloy did not change, indicating that $\mathrm{CoCrCuFeNi}$ high-entropy alloy had good thermal stability. In the subsequent analysis, the changes in material properties could be excluded the factors of phase structure change.

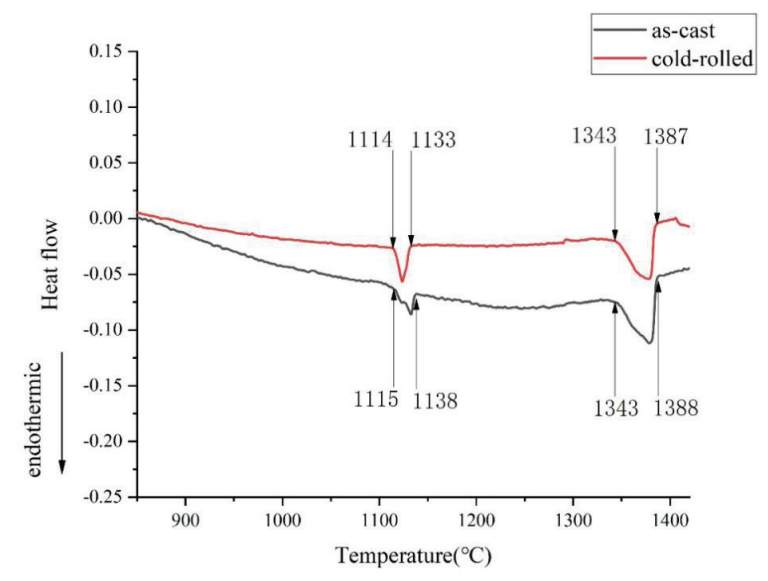

Figure 3. DSC curves of as-cast and rolled CoCrCuFeNi HEA.

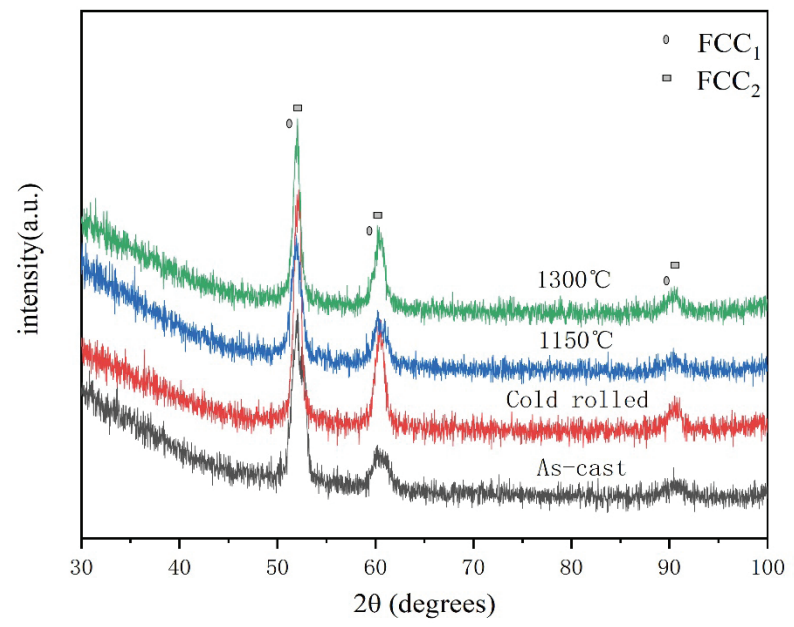

Figure 5: X-ray diffraction patterns of samples in different states. 


\subsection{Microstructure}

As shown in Figure 6, the (a) and (b) are the metallographic diagrams of ingots in different areas, (a) is the upper ends of all the stretch sheet areas cut on the ingots, i.e the clamping area of the stretch sheet, (b) is the central area of the ingot, where the basic stretch sheet deformation area. The dendrite size in (b) region is more uniform and smaller than (a), which makes the tensile effect more stable. (c) shows the microstructure of the parallel rolling direction of the rolled plate. Compared with the as cast structure, it can be seen that the dendrites have obvious deformation, the secondary dendrite arm spacing is reduced, the dendrites have bending deformation, and even have dendrite fracture. (d) shows the microstructure in the vertical direction of rolling. Compared with as cast samples, dendrites also have obvious extrusion deformation. (c) and (d) show that rolling makes the microstructure of the plate have a very large internal stress that can promote the grain boundary remelting in the semi-solid isothermal treatment, there are also a lot of dislocation energy in the crystal. (e) and (f) were the microstructure of the semi-solid isothermal treatment at $1150^{\circ} \mathrm{C}$ for $120 \mathrm{~min}$ and $1300^{\circ} \mathrm{C}$ for $120 \mathrm{~min}$ respectively. Compared with the as-cast and rolled state, the morphology changed from dendrite to spherulite, and the grain size became smaller and evenly distributed, which indicated that the internal stress had been basically released. The higher the temperature of semi-solid isothermal treatment is, the larger the manager size is.
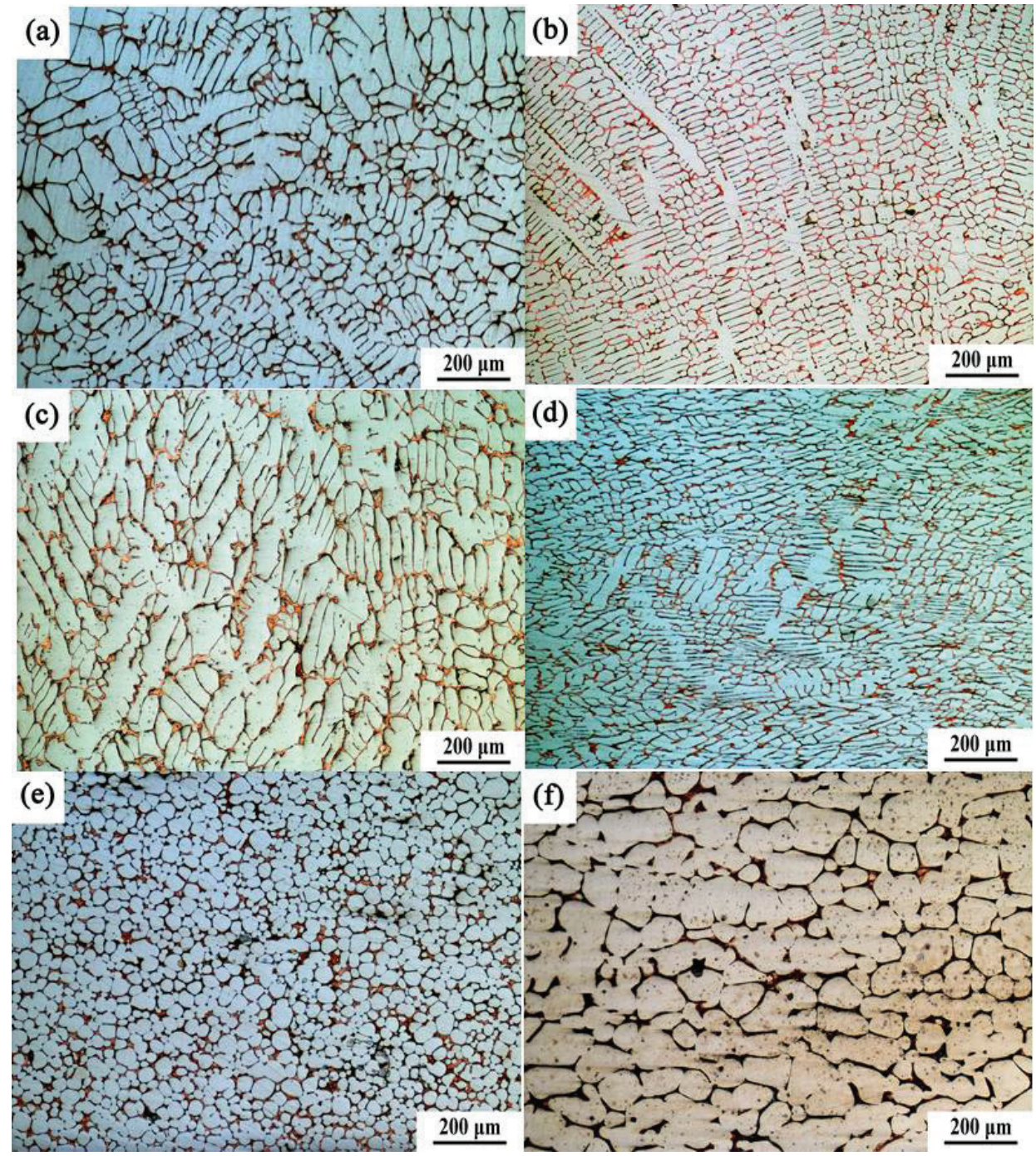

Figure 6. Metallographic photograph: (a) the upper area of the ingot;(b) central region of the ingot (c) parallel rolling direction (d) vertical rolling direction (e) $1150^{\circ} \mathrm{C}, 120 \mathrm{~min}$;(f) $1300^{\circ} \mathrm{C}, 120 \mathrm{~min}$.

Figure 7 shows the metallographic structure photos of semi-solid isothermal treated $\mathrm{CoCrCuFeNi}$ highentropy alloy. The upper side(a), (c), (e) and (g) are the microstructure treated at $1150^{\circ} \mathrm{C}$ for $20 \mathrm{~min}, 30 \mathrm{~min}, 60 \mathrm{~min}$ and $120 \mathrm{~min}$ respectively, while bottom column (b), (d), (f) and $(\mathrm{h})$ are the microstructure treated at $1300^{\circ} \mathrm{C}$ for $20 \mathrm{~min}$,
$30 \mathrm{~min}, 60 \mathrm{~min}$ and $120 \mathrm{~min}$ respectively. At $1150^{\circ} \mathrm{C}$ for 20 minutes, the grain size of FCC2 phase is still relatively small, the morphology and size of primary dendrite remain unchanged, and the secondary dendrite was partially remelted and peeled off to form small spherulites. For 30 minutes, the number of spherulites increased gradually and 
the primary dendrite dissolved and fractured. When the temperature of semi-solid isothermal treatment is $1300^{\circ} \mathrm{C}$, the grain size increases obviously, and with the increase of treatment time, the larger the grain size is.

It can be seen that at $1150^{\circ} \mathrm{C}$ or $1300^{\circ} \mathrm{C}$, the distribution of grains is uniform and the grain size is small when the time of semi-solid isothermal treat is 30 minutes. After 30 minutes, the grains grow with the increase of holding time; The average grain diameter is $50 \mu \mathrm{m}$ and $180 \mu \mathrm{m}$ at $1150^{\circ} \mathrm{C}$ and $1300^{\circ} \mathrm{C}$ for 120 minutes respectively,which indicated that the temperature has a key effect on grain growth.

The variation of grain size can be explained by growth kinetics. In the RAP process of manufacturing $\mathrm{CoCrCuFeNi}$ HEA semi-solid slurry, remelting heat provides energy to support dendrite fuse and spheroidization, while pre deformation stores internal energy. During reheating, recrystallization occurs, and with the formation of liquid phase, spherical grains are easy to form. Driving force of solid recrystallization is produced by the reduction of free energy due to the reduction of elastic storage energy (i.e. bit error energy) ${ }^{[16]}$. During the whole isothermal process of semi-solid remelting, the sharp angle of solid-state FCC2 grains is engulfed by the liquid phase first, and then the grains become larger and rounder.

\subsection{Tensile properties}

Figure 8 shows the stress-strain curves of as-cast and rolled alloys. As you can see, the mechanical properties of the alloy has significant improvement after rolling compared to as-cast alloy, Tensile strength increased from $455 \mathrm{MPa}$ to $945 \mathrm{MPa}$, and Young's modulus is also greatly improved, which in accordance with the previous rolling sample that causes the lattice fracture and grain refinement of the alloy to increase the strength and hardness. However, the elongation after fracture is much lower than that of as cast alloy, which may be due to: (1) Severe plastic deformation causes lattice fracture, grain refinement makes the strength of the alloy increase significantly and decrease the plasticity; (2) Rolling treatment leads to a certain degree of stress concentration in the alloy, which causes some defects, such as cracks, etc., in the process of drawing, which makes the alloy fracture rapidly and leads to low elongation.

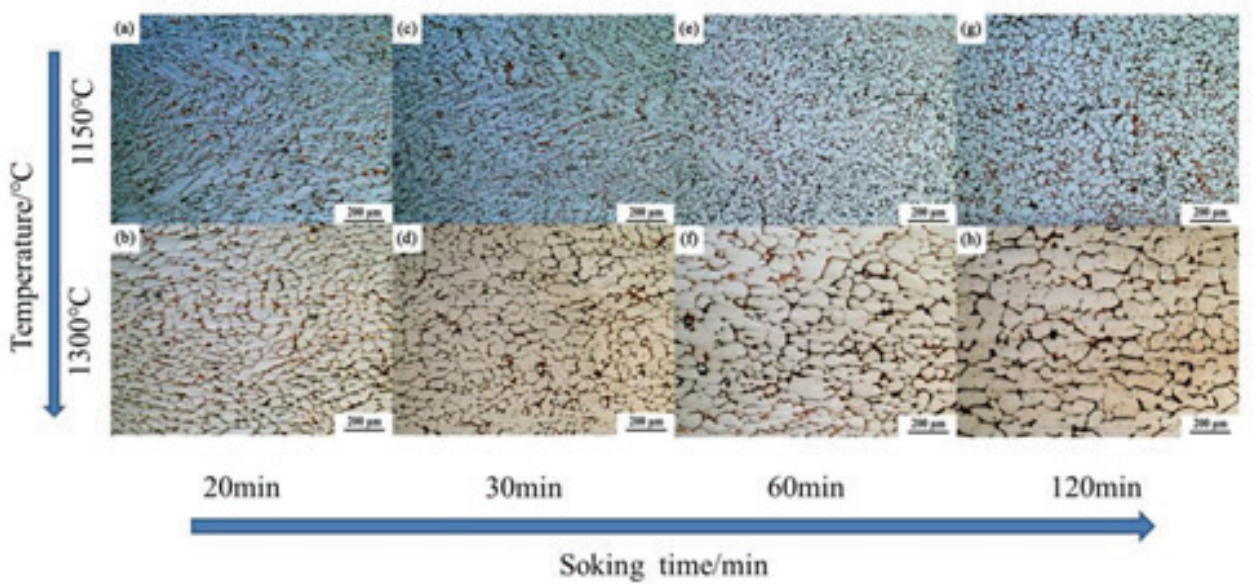

Figure 7. Metallographic photograph: (a) $1150^{\circ} \mathrm{C}, 20 \mathrm{~min}$;(b) $1300^{\circ} \mathrm{C}, 20 \mathrm{~min}$;(c) $1150^{\circ} \mathrm{C}, 30 \mathrm{~min}$;(d) $1300^{\circ} \mathrm{C}, 30 \mathrm{~min}$;(e) $1150^{\circ} \mathrm{C}, 60 \mathrm{~min}$;(f) $1300^{\circ} \mathrm{C}, 60 \mathrm{~min}$;(g) $1150^{\circ} \mathrm{C}, 120 \mathrm{~min}$;(h) $1300^{\circ} \mathrm{C}, 120 \mathrm{~min}$.

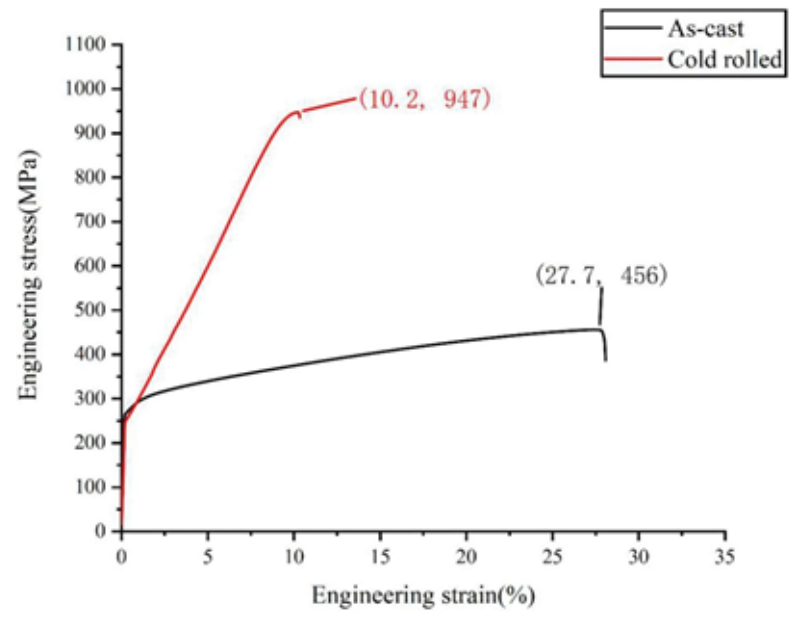

Figure 8. Stress-strain curves of as-cast and rolled alloys. 
Figure 9 and Figure 10 show the stress-strain curves of four groups of tensile experiments treated at $1150^{\circ} \mathrm{C}$ and $1300^{\circ} \mathrm{C}$ for $20 \mathrm{~min}, 30 \mathrm{~min}, 60 \mathrm{~min}$ and $120 \mathrm{~min}$, respectively. As can be seen from Figure 9, the tensile strength of the alloy was $350 \mathrm{MPa}$ when the alloy was isothermally treated at $1150^{\circ} \mathrm{C}$ for $20 \mathrm{~min}$, and the tensile strength increased to $365 \mathrm{MPa}$ when the alloy was kept heat preservation for $30 \mathrm{~min}$. However, the tensile strength decreased to $335 \mathrm{MPa}$ and $305 \mathrm{MPa}$ after the isothermal treatment for $60 \mathrm{~min}$ and $120 \mathrm{~min}$. In FIG.10, the tensile mechanical properties of the alloy treated at $1300^{\circ} \mathrm{C}$ have the same tend as those of the alloy treated at $1150^{\circ} \mathrm{C}$. The tensile strength was $330 \mathrm{MPa}$ at $20 \mathrm{~min}$ of heat preservation, and slightly increased to $335 \mathrm{MPa}$ after $30 \mathrm{~min}$ of heat preservation.

This shows that the mechanical properties of $\mathrm{CoCrCuFeNi}$ high entropy alloy will change with the holding time when the temperature of semi-solid isothermal treatment remains unchanged. When the semisolid isothermal treatment time is less than $30 \mathrm{~min}$, the mechanical properties of $\mathrm{CoCrCuFeNi}$ high entropy alloy become better with the increase of semi-solid isothermal treatment time. When the semi-solid isothermal treatment time is more than $30 \mathrm{~min}$, the mechanical properties of $\mathrm{CoCrCuFeNi}$ high entropy alloy become worse with the increase of semi-solid isothermal treatment time.

When the time of semi-solid isothermal treatment is constant, it can be seen that the tensile strength of the alloy at $1300^{\circ} \mathrm{C}$ is lower than that at $1150^{\circ} \mathrm{C}$ from Figure 9 and 10. The results show that the optimal properties of $\mathrm{CoCrCuFeNi}$ high entropy alloy appear in the semisolid isothermal treatment at $1150^{\circ} \mathrm{C}$ for $30 \mathrm{~min}$, which is the same as the conclusion obtained in the previous metallographic structure analysis. It may be due to the high degree of grain refinement and microstructure homogenization after treatment at $1150{ }^{\circ} \mathrm{C}$ for $30 \mathrm{~min}$, so the strength of $\mathrm{CoCrCuFeNi}$ alloy is better at this time. After the heat preservation, the copper rich FCC1 phase cannot be supplemented by the liquid phase, resulting in shrinkage or porosity.

On the one hand, the composition has changed because of the exchange of elements in the two phases during the semi-solid isothermal heat treatment. According to the similar study in L.J. Zhang ${ }^{[17]}$, the content of $\mathrm{Cu}$ in low melting point FCC1 phase increased to about $83 \%$ and the content of $\mathrm{CoCrFeNi}$ decreased after semi-solid treatment. The enrichment of copper in FCC1 phase results in dendrite segregation, and the difference of composition and structure between the two phases becomes larger. The formation of positive mixing enthalpy between $\mathrm{Cu}$ and other four components, which indicated that it can repel the other four elements and reduce the affinity of twophase structure, so the overall plasticity of the sample is reduced $^{[18]}$; on the other hand, the solid phase of FCC2 grows up slowly and contacts with each other, the liquid phase of FCC1 is enclosed by the solid phase of FCC2 into a closed region. At the end of heat preservation, the copper rich FCC1 phase will produce shrinkage cavity and porosity due to the lack of liquid supplement during the water-cooling solidification process. Under the action of semi-solid isothermal treatment, the shrinkage cavity and porosity changes into crack shown in Figure 11, and the higher the holding temperature is, the more obvious the crack is, resulting in an obvious drop of plasticity.

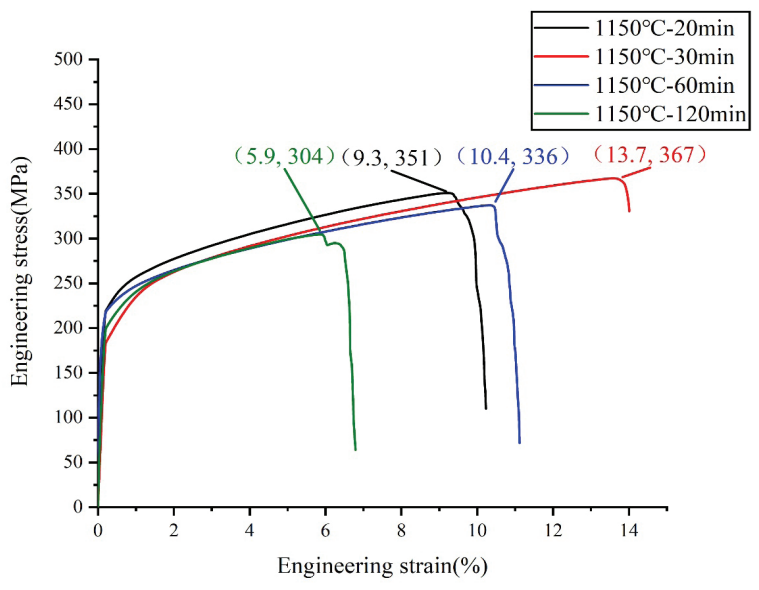

Figure 9. Tensile stress-strain curves of four groups at $1150^{\circ} \mathrm{C}$.

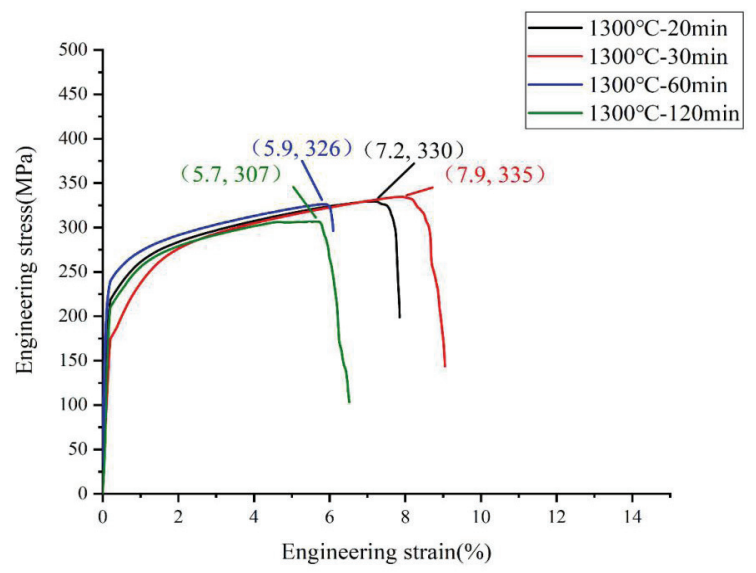

Figure 10. Tensile stress-strain curves of four groups at $1300^{\circ} \mathrm{C}$.

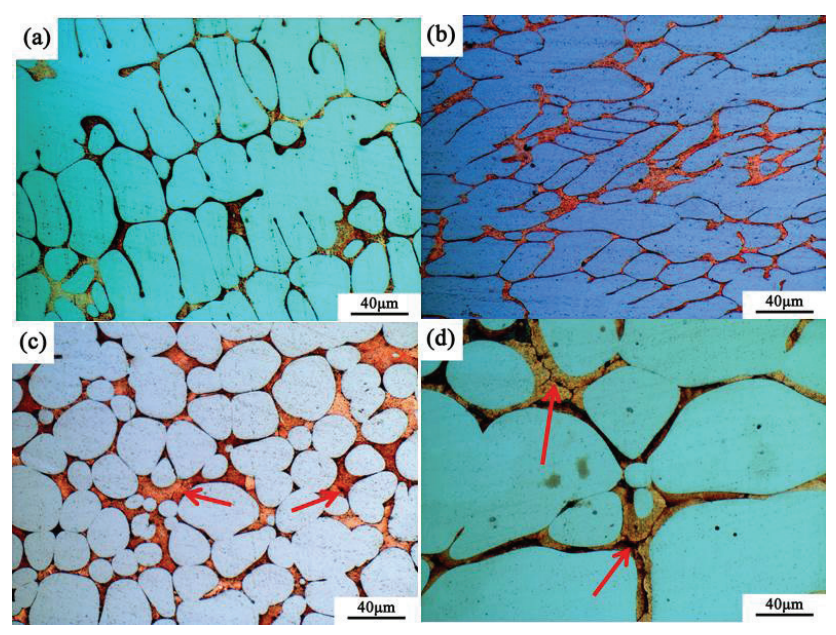

Figure 11. (a) high power in casting state (b) high power in rolling state (c) high power in $1150^{\circ} \mathrm{C}$ for $120 \mathrm{~min}(\mathrm{~d})$ high power in $1300^{\circ} \mathrm{C}$ for $120 \mathrm{~min}$. 


\section{Conclusions}

1) The as-cast CoCrCuFeNi high-entropy alloy has two simple FCC phases, which exists in the form of intercrossing between dendrites and dendrites. The phase structure is not changed by rolling and semi-solid isothermal treatment. The as-cast alloy has $28 \%$ excellent plasticity.

2) After cold rolling with $63 \%$ deformation, the strength of CoCrCuFeNi high entropy alloy increased about $107 \%$. Cold rolling pre deformation destroys the continuous distribution of dendrites, and the deformation energy accumulates at the grain boundary. In the stage of remelting and heat preservation, the release of stored internal energy can promote the melting of grain boundary, increase the proportion of liquid phase and improve the dendrite fuse.

3) The orthogonal experiment of semi-solid isothermal treatment was carried out on the rolled $\mathrm{CoCrCuFeNi}$ high entropy alloy. The results show that for the same holding time, with the increase of holding temperature, the microstructure grains become larger and the mechanical properties decrease; with the same holding temperature, the holding time of the optimal tensile properties is $30 \mathrm{~min}$, and the optimal semi-solid isothermal treatment parameters are $1150^{\circ} \mathrm{C}, 30 \mathrm{~min}$. The corresponding optimum elongation plastic variable is $13.7 \%$, and the strength is $365 \mathrm{MPa}$.

4) The tensile strength and plasticity of the high entropy alloy after isothermal treatment in solid state are lower than that in as-cast. The reason is that the micro cracks in rolling and the oxidation of the cracks in the process of isothermal treatment form, which results in the mechanical properties of the alloy after isothermal treatment is inferior to that of the as cast alloy. More experiments are needed to find other ways to strengthen the high entropy alloy.

Author Contributions: The experiment, data analysis and writing of this article are completed by Lajie Wang. X J Yang puts forward the idea of this article. Jiao Xiong and Jun Liu assist Wang in completing the experiment and writing.

Acknowledgments:This work was supported by the National Natural Science Foundation of China (Nos. 13006707), Science and Technology Project of the Education Department of Jiangxi Province (Nos.171468,181481)

\section{References}

[1] J.W. Yeh, S.K. Chen, S.J. Lin, et al. Nanostructured highentropy alloys with multiple principal elements: novel alloy design concepts and outcomes. [J]. Adv. Eng. Mater 2004 6. 299-303.

[2] Y. Zhang, T.T. Zuo, Z. Tang, et al Lu Microstructures and properties of high-entropy alloys[J]. Prog. Mater. Sci 2014 61, 1-93.

[3] Huang Yuansheng, Cai minghong, Ye Junwei. Study on optical properties of $\mathrm{AlCoCrCu}_{0.5} \mathrm{NiFe}$ high entropy alloy oxide thin film [J]. Surface technology 2016(2), 129-133.

[4] Chen Yongxing, Zhu Sheng, Wang Xiaoming,et al. Laser cladding $\mathrm{Al}_{0.4} \mathrm{CoCu}_{0.6} \mathrm{NiSi}_{0.2} \mathrm{Ti}_{0.25}$ layer of abrasion resistance and high entropy alloys forming mechanism analysis [J]. Journal of Hot WorkingProcess 2018,47,1-6.

[5] Jingwen Qiu, Zhengfan Fu, Di Pan, et al.The Wear Behavior of High-Entropy Alloy Particles Reinforced Titanium Alloy Composite[J]. Journal of Materials Science 2018, 8(10), 1007-1015.

[6]. Z.Q. Fu, W.P. Chen, H.M. Wen,et al.Microstructure and strengthening mechanisms in an FCC structured single-phase nanocrystalline $\mathrm{Co}_{25} \mathrm{Ni}_{25} \mathrm{Fe}_{25} \mathrm{Al}_{7.5} \mathrm{Cu}_{17.5}$ highentropy alloy.[J]. Acta Mater 2016 107, 59-71.

[7] B. Schuh, F. Mendez-Martin, B. Volker, et al. Mechanical properties, microstructure and thermal stability of a nanocrystalline CoCrFeMnNi high-entropy alloy after severe plastic deformation[J]. Acta Mater 2015 96, 258 268.

[8] H. Shahmir, T. Mousavi, J. He, Z. Lu, et al.Microstructure and properties of a CoCrFeNiMn high-entropy alloy processed by equal-channel angular pressing[J]. Mater. Sci. Eng. A 2017, 705, 411-419.

[9] M.C. Flemings.Behavior of metal alloys in the semisolid state Metall. Trans. A 1991, 22,269-293.

[10] T.J. Chen, R.Q. Wang, Y. Ma, et al.Effects of processing parameters on microstructure and ultimate tensile strength of thixoformed AM60B magnesium alloy.[J]. Mater. Res 2012, 15, 687-697.

[11] H.V. Atkinson. Modelling the semisolid processing of metallic alloys[J]. Prog. Mater. Sci 2005, 50, 341-412.

[12] J. Jiang, Y. Wang, G. Xiao, et al.Comparison of microstructural evolution of 7075 aluminum alloy fabricated by SIMA and RAP[J]. J. Mater. Process. Technol 2016, 238, 361-372.

[13] Q. Chen, S.J. Luo, Z. Zhao.Microstructural evolution of previously deformed AZ91D magnesium alloy during partial remelting[J]. J Alloys Compd 2009, 477, 726-731

[14] L Rogal. Semi-solid processing of the CoCrCuFeNi high entropy alloy[J]. Mater. Des 2017, 119, 406-416.

[15] A. Takeuchi, A. Inoue.Classification of bulk metallic glasses by atomic size difference, heat of mixing and period of constituent elements and its application to characterization of the main alloying element[J]. Mater. Trans 2006,46, 2817-2829.

[16] H.V. Atkinson, K. Burke, G. Vaneetveld. Recrystallisation in the semi-solid state in 7075 aluminium alloy[J]. Mater. Sci. Eng. A 2008, 490, 266-276.

[17] Zhang L J , Fan J T, Liu D J, et al. The microstructural evolution and hardness of the equiatomic CoCrCuFeNi high-entropy alloy in the semi-solid state[J]. Journal of Alloys and Compounds, 2018, 745,75-83.

[18] R.N. Singh, F. Sommer Segregation and immiscibility in liquid binary alloys Rep. Prog. Phys. 1997,60,57-150. 